\title{
O capital celebridade $e$ suas articulações em outros campos: a teoria de Bourdieu estendida e o caso de Felipe Neto
}

João Kamradt',2

DOI: $10.1590 / 0103-3352.2021 .36 .246725$

\section{Introdução}

Tornou-se uma banalidade afirmar que as celebridades são uma característica comum, dinâmica e, também, essencial das culturas e das sociedades contemporâneas ocidentais. Nos mais distintos campos sociais, como o econômico, o cultural e o político, a figura da celebridade representa um recurso valioso seja no sentido de expressar o poder quanto no de alcançá-lo. Levando-se em conta o argumento de Couldry (2003) de que os meios de comunicação são os gatekeepers privilegiados do nosso tempo, bem como os pontos de acesso ao centro social, estabeleceu-se uma distinção entre as pessoas comuns e as midiáticas. Logo, o indivíduo midiático ganha uma importância que é notada pelos outros.

Podemos constatar essa suposição quando assistimos a infinidade de shows de talentos e de reality shows no qual um grande contingente de pessoas “comuns" luta pela fama. Além disso, é cada vez mais nítido o quanto celebridades da mídia e do entretenimento buscam acessar o campo político - além de outras esferas, como a econômica. Essa incorporação profunda

1 Doutor em Sociologia e Ciência Política pela Universidade Federal de Santa Catarina (UFSC), Programa de PósGraduação em Sociologia e Ciência Política, Florianópolis, SC, Brasil.

2 Professor da Faculdade IELUSC, Curso de Comunicação, Joinville, SC, Brasil. E-mail: joaokamradt@gmail.com 
das celebridades no seio da sociedade e da cultura vem atraindo a atenção de estudiosos cada vez mais, como atestam os estudos de Wright Mills (1982), Boorstin (1971) e, mais recentemente, Marshall (1997), Rojek (2008), Turner (2004), Dahlgren (1995), Street (2004, 2012), Wheeler (2012), entre outros.

A diversidade de abordagens e de tradições teóricas no chamado de campo de estudos sobre as celebridades gerou imprecisões, como a dificuldade de compreender e delimitar que em uma sociedade midiática a celebrização constitui um capital por si só. Na atual sociedade midiática, cada vez mais digitalizada, as elites políticas tradicionais e os políticos profissionais vêm perdendo espaço e caindo em declínio de confiança e de popularidade. A solução por parte desses indivíduos foi recorrer às táticas populistas (ALBERTAZZI; McDONNELL, 2015) ou a campanhas personalizadas (CAIRNEY, 2007). Desse modo, a elite política precisou modificar suas táticas, como visto nas campanhas de Barack Obama, em 2008, para a presidência dos Estados Unidos, de Tony Blair, em 1997, para primeiro-ministro da Inglaterra, e de Kevin Rudd, para primeiro-ministro da Austrália, em 2007 - todos considerados políticos celebridades por terem usado a cultura popular e o entretenimento em seu favor para conquistar votos (MARSH; 'T HART; TINDALL, 2010; STREET, 2004, 2012; WHEELER, 2012). Isso ocorreu na esteira da manifestação política de famosos, que eram tanto diretos quanto estavam mais próximos do eleitor, a exemplo de Bono Vox, vocalista do U2, que convocou os líderes dos sete maiores países do planeta para discutir a questão da fome na África.

Nesse contexto, a celebridade seria apenas uma faceta do capital simbólico? Outra face do capital político? Ou, por vivermos em uma época na qual os políticos são cada vez mais midiáticos, agora a celebrização configura um capital próprio que funciona em outros campos sociais, ajudando a chamar a atenção para determinada situação ou mesmo a promoção de algum indivíduo em específico? Caso seja isso, que tipo de capital vem a ser? Partindo dos conceitos consagrados por Bourdieu (2007, 1989, 1996), defendo que as celebridades se tornaram um capital específico devido ao papel fundamental que desempenham na transformação do campo político e do campo simbólico. Para tanto, além de mostrar isso teoricamente, apresento uma análise de como o influencer digital Felipe Neto vem articulando o seu capital de celebridade para falar sobre política para milhões de pessoas. 


\section{A cultura afeta o político}

Embora as celebridades e o capital resultante de sua presença sejam o foco deste artigo, faz-se necessário ressaltar que essas figuras são apenas um sintoma do quanto a cultura de massa e do entretenimento impactam os campos político e econômico. O que há em comum em jogar videogame, assistir a um episódio de uma série de televisão ou um filme, ler um livro ou quadrinhos, ouvir uma música, um podcast ou usufruir de tantas outras formas de entretenimento? Todas têm a capacidade de fazer com que os indivíduos tomem posicionamentos morais. Uma obra cultural capacita o indivíduo a refletir, criar analogias e compreender como culturas diferentes alteram a forma de viver dos indivíduos. Por muito tempo visto apenas como um escape para os sujeitos, o entretenimento tem hoje um papel central na maneira pela qual os indivíduos moldam as preferências e gostos, como decidem em quem votar e a partir de quais valores farão essa escolha. O entretenimento mostra ser mais do que o puro escapismo. Vivemos atualmente em uma sociedade midiática, na qual "as mídias perdem este lugar de auxiliaridade e passam a se constituir uma referência engendradora no modo de ser da própria sociedade, e nos processos e interação entre as instituições e atores sociais" (NETO, Antônio, 2008, p. 93).

Como a mídia possui um papel expressivo na sociedade e o que mais ela produz é entretenimento, esse contexto gera um peso maior na vida dos sujeitos. É visível o impacto cultural causado pela mídia - sem dúvida, um dos motores da sociedade. Daí a importância dada para aqueles que recebem maior cobertura midiática. O mundo intensamente mediado da cultura popular informa e influencia a esfera política. Como Street (1997, p. 5) afirma: “"nós' lemos nossos políticos através de seus gestos e seus rostos, da mesma forma que lemos artistas na televisão". E se artistas de televisão, apresentadores de programas de auditório, cantores ou jogadores de futebol ganham amplo espaço e simpatia na mídia, é natural que haja identificação do público com essas celebridades midiáticas. Em outras palavras, ser um bem-sucedido produto midiático comporta paralelos com o trabalho de representar politicamente a população. Thompson (2005, p. 36-39) enfatiza que o representante político precisa ter a capacidade de se tornar visível para estar apto ao círculo eleitoral. Cardo (2014) alega que a visibilidade estabelecida pelos meios 
de comunicação permite aos políticos substituírem o seu "distanciamento impessoal" ou percebido por uma "intimidade mediada" e estabelecer uma relação particular com o seu eleitorado. "A sugestão é de que, através dessa intimidade, os políticos adquirem a capacidade de se apresentar como 'um de nós"' (CARDO, 2014, p. 147). Além disso, os políticos interessados em alcançar a nova geração foram obrigados a se reinventar, sendo forçados a considerar novos formatos, que borraram e desfizeram a linha entre o entretenimento e a informação.

A cultura popular não é apenas fonte para se obter conhecimento político, mas também para alcançar a moralidade política. Como defende Inthorn e Street (2011, p. 339): "ideias de certo e errado, por exemplo, são exploradas em shows de talentos, em particular sobre o tratamento dos concorrentes e o comportamento dos juízes". Como Dahlgren (2009) comenta, essas representações, chamadas de "protopolíticas", são uma visão preliminar da compreensão política. Tanto Inthorn e Street quanto Dahlgren enfatizam que o papel da cultura popular é maior no desenvolvimento da compreensão política do que apenas transmitir ideias e informações: "os jovens trazem juízos estéticos e outras opiniões para suportar as fontes do seu prazer cultural, discriminando entre o 'autêntico' e o 'falso', o 'autoritário' e o 'mal-informado'” (INTHORN; STREET, 2011, p. 339).

Inthorn e Street (2011) argumentam que discussões sobre uma obra cultural fazem com que os indivíduos se envolvam em discussões sobre "protopolítica" e sejam obrigados a pensar sobre as forças que moldam o mundo e as possibilidades que elas criam. Como exemplo, os autores usam os reality shows, que forneceriam uma visão sobre como o mercado de trabalho funciona. Ao fazer isso, eles não estão fazendo referências a políticas liberais, mas criam e envolvem os participantes em questões de competição e de mérito. "Perguntas de como o mundo faz e deve fazer para reconhecer o talento e quais as implicações que elas têm para o papel do Estado, sustentam as ideologias políticas concorrentes" e na medida em que debates sobre reality shows provocam essas realizações deve-se "considerá-las protopolíticos" (INTHORN; STREET, 2011, p. 348). Tudo isso derrubaria o mito de que os jovens não estão interessados em política. De acordo com Inthorn e Street, eles apenas não estariam interessados na política partidária. 
Na sociedade midiática, cada vez mais digitalizada, as elites políticas tradicionais e os políticos profissionais vêm perdendo espaço e caindo em declínio de confiança e de popularidade. Compreender o ambiente cultural que nos cerca é fundamental para a nossa formação política: “a cidadania não é apenas uma capacidade cognitiva, mas também uma prática cultural” (VAN ZOONEN, 2005, p. 553). A atenção que se presta às narrativas culturais é motivada pela necessidade de enxergar como as audiências estão vendo e ouvindo. Van Zoonen diz que há duas dimensões para isso: a afinidade e a avaliação. A afinidade trata da maneira como o público se identifica com os personagens ou com as situações retratadas. Já a avaliação estabelece uma identidade coletiva, um senso de quem somos e de quem, em contraste, são "eles". Esse processo ganha um significado político ao tratar sobre quem são os representantes das pessoas e quem pode falar em seu nome. Esta questão ganhou força nas últimas duas décadas com a discussão sobre a política da celebridade (WEST; ORMAN, 2002; STREET, 2004).

O entretenimento popular é visto como mais do que um suporte para ampliar o conhecimento, mas também uma contribuição genuína para as identidades dos sujeitos. Inthorn e Street (2011) defendem que qualquer reivindicação sobre o significado político da cultura popular deve derivar inicialmente dos prazeres que essa cultura gera, bem como da importância que lhe é atribuída, e não ao contrário (ou seja, ao interesse político que se volta para a cultura). E, na mídia, é a celebridade quem dispõe da maior aparição, passeando no imaginário do público e tendo, a seu alcance, a chave para entrar na casa dos indivíduos. Corner e Pels (2003) fazem um balanço das diferenças entre as esferas existentes na política. Conforme apontam, existe a esfera política, a esfera pública e popular e a esfera privada. Na esfera política, argumentam que nada há para ser mediado, sendo o trabalho feito longe dos olhares do público. Enquanto isso, a esfera pública e popular passa a ser mediada pelo político atuando como uma figura pública. Aqui, Corner e Pels fazem a analogia de que a esfera política deve ser vista como "local de trabalho" enquanto a esfera pública e privada como uma "loja", com a separação entre a produção e o consumo da política. Já a esfera privada ampliou a sua importância com a ascensão da celebridade política. Isso porque as audiências que consomem entretenimento não são homogêneas, podendo interpretar as celebridades e os meios 
de comunicação de formas distintas (ABERCROMBIE, LONGHURST, 1998). Nessa lógica, a celebridade está aberta a uma variedade de "configurações coletivas" (MARSHALL, 1997) de etnia, gênero e nacionalidade. "Assim, entendidas como acontecimentos, as celebridades também são vistas como fonte de sentido para a compreensão do mundo" (SIMÕES, 2014, p. 47).

Como Holmes (2010) comenta, os processos de destradicionalização significam que os indivíduos precisam cada vez mais das emoções em um mundo em que as formas estabelecidas de ser e fazer não são mais dadas como garantidas. Esses processos de mudança social demonstram que a política eleitoral deixou de ser organizada em torno das divisões de classe social. Ao invés de aparecerem como especialistas em políticas públicas ou como representantes de uma determinada classe, os políticos aparecem cada vez mais como indivíduos que possuem conexão com a vida cotidiana do eleitor. Esse cenário faz com que suas reivindicações de liderança se fundamentem em conexões diretas com a vida cotidiana, o que proporciona uma compreensão das preocupações e das questões relevantes para os indivíduos comuns (MANNING; HOLMES, 2014).

\section{As celebridades enquanto conceito}

Celebridades são um fenômeno moderno. Na sociedade contemporânea, o termo celebridade, como demonstra Rojek, está associado a fama, natureza temporária, volúvel e mercado de sentimentos humanos - tudo em um contexto no qual ocorrem relações episódicas, anônimas, em que pode haver mudanças velozes na vida social e econômica do indivíduo, sustentadas pela atribuição de um status glamouroso a um sujeito dentro da esfera pública (ROJEK, 2008, p. 11). É pela possibilidade de terem as suas imagens propagadas imensamente por meio dos meios de comunicação de massa que esses indivíduos ganham o status de celebridades. Braudy (1997), Gabler (2000) e Rojek (2008) argumentam que a posição social de prestígio desfrutada hoje por celebridades resulta de três grandes transformações sociais sofridas no último século: a democratização, a industrialização e o processo de secularização. Segundo esses autores, a combinação da industrialização com a democratização das nações no século XVIII fez com que a ordem social anterior, baseada na ramificação de laços familiares, perdesse força. A democracia trouxe 
a promessa da igualdade entre os indivíduos. Do mesmo modo, a industrialização rompeu com os modos de produção estabelecidos até então, gerando, assim, uma oportunidade para que os indivíduos pudessem buscar padrões de vida mais elevados. Para Weber (2012), o processo de secularização fez com que uma grande parte da vida social dos indivíduos fosse reduzida a uma lógica racional, resultando em uma separação ou abandono gradual das formas tradicionais de estruturação social baseadas na religiosidade ${ }^{3}$. Podemos dizer que o processo de secularização estaria relacionado à formação do mundo moderno, em que ocorreu a redução das teocracias e o surgimento das instituições modernas. Logo, o declínio da religião, aliado à democratização e à industrialização, criou uma estrutura social mais fluída, com menor número de distinções sociais e uma situação que, "ao menos teoricamente, desse aos indivíduos condição de se superar” (GABLER, 2000, p. 194).

Nesse contexto, surgiram as celebridades. De acordo com o entendimento de Turner, uma de suas características é de que "a celebridade moderna não pode reivindicar nenhuma realização especial para si além da atenção pública" (TURNER, 2004, p. 3). Para Thompson (2005, p. 220-225), as celebridades têm como característica fundamental possuir admiradores e fãs. $\mathrm{O}$ autor alega ainda que as celebridades são um fenômeno definidor da modernidade, dada a necessidade da formação de relações de intimidade com indivíduos distantes e diferentes entre si. Esse elemento, segundo ele, é o que daria base para os famosos serem vistos como representantes políticos. Como Street aponta, as celebridades criam vínculos afetivos com seus admiradores/seguidores, abrindo espaço para que um artista venha representar aqueles que o admiram. "Eles dão voz política aos que os seguem, tanto em virtude das condições políticas quanto por meio de sua arte" (STREET, 2004, p. 449). Wheeler acredita que isso gera o seguinte efeito: "os deveres cívicos tradicionais estão sendo substituídos por formas alternativas de participação. Dentro deste novo ambiente político, diferentes tipos de agência, como a política de celebridade, tornaram-se forças centrífugas para o engajamento público" (WHEELER, 2012, p. 408). Nesse contexto contemporâneo, a teoria de campo e capital de Bourdieu precisa ser estendida. A celebrização dos indivíduos pede espaço próprio.

3 Como Sell afirma, a secularização é "uma tentativa de compreensão da natureza do moderno em sua relação histórica com o religioso" (SELL, 2015, p. 12). 


\section{Entre o campo e capital político e simbólico, o capital de celebri- dade ganha espaço}

Para saber se o processo de celebrização se constitui como um novo tipo de capital ou se é uma ampliação do capital simbólico, se faz necessário retornar, mesmo que brevemente, aos conceitos de campo, capital e habitus de Bourdieu. O sentido que Bourdieu confere ao campo é o de um sistema de relações sociais que estabelece como legítimos determinados objetivos, os quais se impõem naturalmente aos agentes participantes. Cabe a esses agentes interiorizar o próprio campo, incorporando as suas regras e práticas, elemento a que Bourdieu dá o nome de habitus. Desse modo, cada campo "é um campo de forças dotado de uma estrutura, e também um campo de lutas para conservar ou transformar esse campo de forças" (BOURDIEU, 2009, p. 69).

Recorrendo ao conceito de campo, é possível compreender a interação entre a política e os meios de comunicação, já que as duas esferas, mesmo se guiando por diferentes lógicas, interferem uma na outra. Cada campo é definido por uma imposição de critérios próprios, em especial por aqueles que fixam os objetivos apresentados como "naturais" para todos que participam. No caso em questão, é a busca por um maior poder político. Logo, o campo seria "um universo obedecendo às suas próprias leis" (BOURDIEU, 1989, p. 52). O capital político é essencial para indicar o reconhecimento social que permite alguns sujeitos serem facilmente aceitos como atores políticos. "O poder político é um capital de reputação, ligado à notoriedade, ao fato de ser conhecido e reconhecido, notável" (BOURDIEU, 2011, p. 204). Como se vê, é fundamental dispor de capital para se avançar na carreira, seja ela qual for. Ao mesmo tempo, alcançar cargos mais altos na hierarquia do campo político acaba por demonstrar uma ampliação deste capital.

Os trabalhos de Bourdieu analisam a combinação entre as ações práticas dos indivíduos e suas percepções, fortemente influenciadas pela cultura, além da condição de classe. Logo, o habitus no qual tanto o indivíduo existe quanto o que veio a adquirir ao longo da vida se apresenta como importante para determinar como é possível adquirir diferentes tipos de capitais e utilizá-los. O habitus - "história tornada natureza" - é, ao mesmo tempo, um conjunto de princípios geradores de práticas (distintas e distintivas), mas geralmente automáticas, irrefletidas; além de uma série de esquemas classificatórios 
(princípios de visão e divisão) e gostos diferentes. O habitus, desenvolvido e transformado ao longo da vida, carrega as experiências da vida familiar e na escola, as quais lhe conferem o caráter de classe. A socialização realiza a incorporação dos habitus de classe e produz a filiação da classe dos indivíduos, reproduzindo-a e ao próprio habitus (BONNEWITZ, 2005, p. 75). O habitus é um saber prático, um conhecimento voltado à ação. Resulta em reações espontâneas, irrefletidas, mas também afeta as representações e influencia a compreensão do mundo e a interpretação dos discursos. A autoridade está nas falas, modos, gestos, bem como nas atitudes e no desenho das relações. A leitura de tudo isso pelos sujeitos é afetada pelo habitus.

Nesse contexto, uma vasta literatura, que inclui o próprio Bourdieu (1996), aponta para a presença crescente da mídia como fonte de capital político (mesmo que essa terminologia não seja usada sempre). De fato, a visibilidade nos meios é uma condição fundamental para o reconhecimento público, em qualquer área de atividade, nas sociedades contemporâneas. Logo, os meios de comunicação geram "atalhos" na carreira, na medida em que indivíduos com alta visibilidade midiática podem postular cargos mais elevados do que seria esperado em um desenvolvimento "normal" da carreira política. Argumento aqui que não é necessariamente capital político o que a mídia gera, mas, sim, capital de celebrização, que, caso convertido, resultaria em capital político.

Bourdieu identifica que indivíduos de determinado campo social conseguem angariar capital suficiente (simbólico, cultural e econômico) para se inserirem em outro campo. Como postula, isso é possível por meio das reconversões, que ocorrem “[...] sempre que, para manter sua posição na estrutura social e as propriedades ordinais que lhe estão associadas, os agentes são obrigados a proceder a uma translação acompanhada por uma mudança de condição" (BOURDIEU, 2007, p. 122). Dito de outro modo, a reconversão do capital é realizada pelos agentes "sob uma espécie particular em uma outra espécie, mais acessível, mais rentável e/ou mais legítima, em determinado estado do sistema [...]" (BOURDIEU, 2007, p. 122). Ou seja, celebridades da $\mathrm{TV}$, do campo esportivo, oriundas de programas de auditório ou empresários com sucesso econômico, após alcançarem sucesso dentro de sua área, passam a galgar posições em campos diferentes. Nesse caso, buscam um cargo público legitimado pelo voto. 
Nessa perspectiva, estratégias de reprodução constituem um conjunto de práticas por meio das quais grupos ou indivíduos conservam ou ampliam os seus patrimônios, melhorando ou mantendo suas posições na estrutura das relações sociais. Desse modo, são um produto do habitus e possuem uma parte de adaptabilidade ao presente, o que encerra uma dose de antevisão do futuro. Tais estratégias dependem da disponibilidade de certos instrumentos de reprodução e da estrutura do capital que será reproduzida, ou seja, do potencial e do volume atual de cada espécie de capital e do peso relativo de cada tipo de capital na estrutura patrimonial. Também precisa ser considerado o estado em que foram encontrados estes instrumentos de reprodução, como o mercado de trabalho, as leis de herança e sucesso e o sistema escolar. A situação dessas ferramentas de reprodução irá depender das relações de força expostas a cada momento no campo. Se houver qualquer mudança, isso implicará na necessidade de reestruturação da sua estratégia de reprodução. Logo, é comum que essa reestruturação ocorra pela conversão de um tipo de capital em outro, mais legítimo e operante segundo determinada circunstância, já que isso resultará na alteração da estrutura patrimonial.

Segundo Bourdieu (2007), existem dois tipos de estratégias de reconversão. A primeira é constituída pelas reconversões verticais, entre agentes situados dentro do mesmo campo. No campo político, por exemplo, um indivíduo pode se eleger vereador, depois virar prefeito, deputado estadual, federal e assim por diante. Todos movimentos ocorrem em um sentido vertical dentro do mesmo campo, sendo orientados de acordo com as regras daquele campo, cuja característica principal é o acúmulo de recursos e capitais para os integrantes deste campo. Já a segunda estratégia de reconversão é menos comum: o seu principal objetivo é o deslocamento de um indivíduo de um campo para outro. Nessa lógica, o cantor, o jogador de futebol ou o empresário de sucesso, que possui capital em seu respectivo campo (cultural, econômico, simbólico) e que detém certos recursos, optam pela estratégia de reconversão transversal. Isso só é possível quando a manutenção da posição de classe dentro da estrutura social passa por um deslocamento que muda sua condição. Logo, a mudança na estrutura patrimonial irá resguardar o volume de capital e manter a mesma posição.

A popularidade e a notoriedade são dois dos elementos que podem ser alcançados em outras áreas antes de serem convertidos em capital político. É 
o caso de celebridades, como artistas, intelectuais ou esportistas quando entram na vida política ou se posicionam politicamente, a partir daí buscando articular mudanças de posição. Como defende Driessens, não há dúvida sobre o poder que a celebridade gera. "Em vários campos sociais, como o campo político, cultural ou econômico, a celebridade tornou-se um recurso de poder valioso" (DRIESSENS, 2013, p. 543). Outra espécie de capital convertido é o heroico, que acaba sendo uma subespécie do capital simbólico.

Como se sabe, o campo midiático permite a construção de narrativas heroicas, de lutas travadas, vencidas ou perdidas de maneira honrada. Logo, é factível encontrar políticos que busquem ampliar seu capital político ao se inserirem sem cerimônia no campo midiático e de celebridades, intentando ampliar sua capacidade de mobilização política. Em uma época em que os políticos precisam cada vez mais da visibilidade e que muitas celebridades perseguem incessantemente um espaço no campo político, como transcorreu a aproximação entre as celebridades e a política? Só havia um caminho: a mídia. Como Dahlgren (2001, p. 85) argumenta, "a política não existe mais como uma realidade ocorrendo fora da mídia, para ser 'coberta' por jornalistas". Ao contrário, a política é cada vez mais organizada como um fenômeno da mídia, o qual é planejado e executado para e com a cooperação da mídia. Isso gera um senso de que a política está sendo construída e transformada pela mídia que formalmente a reporta.

\section{A mídia e a política convergem}

Para compreender como a celebridade passou a ser usada primeiramente como um capital simbólico em vários campos, como no político, formando depois os próprios campo e capital, faz-se necessário entender como a mídia e a política passaram a disputar o mesmo espaço: o do entretenimento. Podemos apontar olhares distintos sobre a mídia e a política. Para Meyer (2008, p. 10), “[...] a mídia de massa não apenas reflete a realidade política, mas também cria uma 'realidade' política feita sob medida para atender a seus próprios interesses". O argumento que Meyer usa é de que a "democracia midiática" faz com que os atores políticos tenham de adaptar as suas ações para apresentá-las à mídia, seguindo o código adotado por esta. Nessa lógica, o que mais importa é o resultado obtido a partir da leitura de como a mídia 
irá noticiar determinado assunto. Isso transforma o processo político, fazendo que os políticos se destaquem não pelo trabalho como indivíduos públicos, mas pelo modo como mobilizam a mídia a seu favor.

Na medida em que os atores da elite do sistema político depositam suas esperanças na equação básica da democracia midiática, ou seja, de que a publicidade é sinônimo de sucesso, eles se rendem às restrições temporais características da produção da mídia, porque supõem que este é o preço que devem pagar para conseguir apoio por parte do público. (MEYER, 2008, p. 76).

Essa modalidade seria composta por atores políticos que se destacam na mídia, com o público que consome mídia e pelo uso permanente das pesquisas de opinião. Isso faria a política e a mídia se tornarem indissociáveis. Baseandose no conselho de Maquiavel de que os príncipes não precisam ter boas qualidades, mas têm de parecer tê-las, Corner (2000) chama a atenção para a maneira como as aparências particulares são necessárias à condução da política democrática moderna. Tais aparições são construídas através das performances feitas e dos estilos adotados pelos políticos. São performances e estilos que existem dentro da mídia de massa e dependem dela. Rubim (2004) defende que a política precisa, sempre, de um conjunto de práticas, instituições e de atores capazes de produzir sua própria representação na sociedade. Segundo ela, a plasticidade gerada por esse regime da imagem faz com que a política necessite de uma dimensão estética: "A necessidade de considerar tal dimensão torna-se algo essencial nessa nova circunstância societária" (RUBIM, 2004, p. 7).

Meyer defende que a centralidade dos meios de comunicação na sociedade impele o transbordamento dessa influência em diversas áreas, mas, principalmente, na política, com cada um tendo de se adaptar aos códigos usados na mídia. Ele explica que essa adaptação dos outros campos à mídia ocorre tanto no sentido de os meios mostrarem a política de acordo com as suas regras quanto na maneira como a natureza da política acaba transformada por causa do desejo de se submeter ao poder das regras midiáticas. Isso faz com que os indivíduos modulem suas personalidades para alcançar bons resultados na mídia. Conforme aponta Meyer, na personificação, as pessoas são transformadas 
em personagens por meio da junção de suas expressões verbais e corporais, de modo "que possam personificar qualidades, forças, tendências, virtudes, programas ou poderes que tenham um impacto decisivo na cultura política e na mitologia de um país" (MEYER, 2008, p. 61).

Mas a ideia de colonização da mídia de Meyer é contestada por outros pesquisadores. Street, por exemplo, compreende o entretenimento em si como uma forma de política. Para ele, o entretenimento não é apenas diversão associada à alienação ou ao domínio político, devendo ser pensado como uma ferramenta de ação política, usada até mesmo como forma de resistência a sistemas hegemônicos. Nesse sentido, se Meyer acredita que a mídia colonizou a política, Street $(1986,1997,2001)$ defende que o entretenimento deixou de ser apenas diversão. A sua justificativa é a de que a mensagem voltada a entreter alcança muito mais pessoas, assim como consegue auxiliar na construção de identidades e comunidades.

Já para Gomes (2007), a política contemporânea é uma política de imagens baseada na visibilidade dos seus agentes. Assim, a imagem pública de alguém na política privilegia a aparência, o carisma, o espetáculo, a teatralização e o simulacro. Para ele $(2004,2007)$, a política da imagem possui três funções atualmente. A primeira função é a de criar, produzir e construir a imagem dos atores públicos; a segunda consiste em ajustar a imagem entre o personagem real e o perfil ideal gerado pela expectativa do público. Por fim, a terceira é administrar, gerir e controlar sua imagem pública. Segundo Gomes, desse modo, a principal questão acerca da imagem pública é a disputa em torno do que ele chama de "esfera de visibilidade pública", que seria uma combinação da esfera política e da esfera midiática, além da dimensão pública no sentido habermasiano.

Como as elites políticas precisam constantemente se legitimar, a mídia é o caminho natural. Além disso, há a necessidade constante de cultivar uma imagem midiática positiva perante o público, para obter vantagem frente aos outros candidatos - o que leva rapidamente a uma política de encenação ou de pseudoeventos, para ficar na terminologia de Boorstin (1971). Por sua vez, ao legitimar o poder que dispõem por meio da mídia, os atores políticos buscam consenso. Isso faz com que a mídia molde a esfera pública, já que os atores políticos sentem que a única forma de alcançar o seu eleitorado é a de adotar os códigos básicos midiaticamente utilizados. 
Hart (1999) alega que a televisão reescreveu a relação entre eleitores e política, moldando a maneira como as pessoas veem e se sentem sobre a política. Essa afirmação não se refere apenas às mudanças instrumentais na comunicação política; ao contrário, trata-se da transformação da política como um campo de atividade. Tal pensamento é capturado em expressões como "nova política" ou "política mediada", ou seja, a política existe apenas como uma série de representações midiáticas. Tal ideia é ilustrada por Kertzer (2011), que sustenta que a política é constituída por rituais, sendo que destes deriva o poder de suas representações simbólicas. É isso que leva a política ao entretenimento. Entre tantas visões que se diferenciam sobre a mídia e a política, uma interpretação que considera tanto o peso do entretenimento quanto o da política é proposta por Van Zoonen. De acordo com ela, é inocência acreditar que a política atrairia os olhares do público unicamente por suas características. $\mathrm{O}$ seu entendimento é o de que as reuniões, deliberações e tomadas de decisão entre Legislativo e Executivo são de interesse apenas daqueles que participam diretamente. Para alcançar o público, a informação precisaria de uma outra linguagem, acessível a todos. E aí entra o entretenimento, que não só pode facilitar o alcance da mensagem como também ofertar formas até então desconhecidas de tomada de decisões e de mobilização social (VAN ZOONEN, 2005).

Segundo a autora, a quebra das fronteiras entre política e entretenimento é mais um exemplo de um processo de disseminação de distintos formatos da mídia por distintos segmentos da sociedade. A ação política e a participação dos cidadãos estariam em equivalência, conforme aponta. Além disso, as novas formas de midiatização da sociedade fizeram com que surgissem novas formas de engajamento e participação dos cidadãos. Nesse novo cenário, a política luta por espaço contra o entretenimento, utilizando, por isso, seus formatos, gêneros e práticas. Nesse cenário, "políticos precisam alternar constantemente entre as demandas da política e do entretenimento para manter sua posição e status no campo político, bem como sua presença na cultura cotidiana de seus eleitores" (VAN ZOONEN, 2005, p. 69).

Dessa forma, o que Van Zoonen propõe é ir além da dicotomia política e entretenimento, entre aquilo que é divertido e o que é sério, sugerindo que deve haver uma convergência entre a política e entretenimento. Nessa ótica, não entende que a política irá sofrer uma perda, mas sim que adaptará seu 
comportamento aos interesses da população, realizando uma aproximação das linguagens que permitem que ideias complexas trabalhadas no mundo político cheguem a mais pessoas: "Na carga crescente de textos e imagens do entretenimento, a performance individual dos políticos é um caminho mais curto para oferecer aos cidadãos a informação necessária para fazer seus julgamentos políticos" (VAN ZOONEN, 2005, p. 69). É essa convergência entre a política e o entretenimento que levamos em conta para compreender como o capital de celebridade é utilizado na sociedade contemporânea.

\section{A celebridade como campo e capital próprio}

Diante da convergência da mídia na política, é natural que o capital de celebridade se configure como um poder. Por isso, retorno à questão: a celebridade pode ser considerada um campo e um capital próprio? Defendo que sim. Ser uma celebridade significa ser conhecido. Ser famoso é ter um rosto público. Heinich (2012), ao tratar sobre a história da visibilidade nas sociedades ocidentais, investiga a transformação ocorrida na forma como as figuras públicas se estabelecem após o surgimento e a expansão da mídia. Segundo a autora, antes do século XX, não era o rosto que era conhecido, mas sim os nomes ou os milagres feitos pelos indivíduos. Só posteriormente, faces eram atribuídas a esses rostos. Defende ainda que a visibilidade midiática inverteu esse processo, já que, agora, uma face é reconhecida sem que seja necessário um nome. A autora deixa claro que isso não acontece em decorrência de um crescimento na difusão das imagens (o que ocorreu ao longo do século XX), mas pela predominância de uma nova lógica no reconhecimento de um indivíduo por outro, oriunda desse novo processo de visibilidade midiática. Como Lana (2013, p. 18) enfatiza:

Antes consequência do mérito, a visibilidade passa a antecedê-lo, o que gera um novo dividendo para a construção das figuras públicas - a própria visibilidade, que se torna um tipo de capital usado como moeda de valor para se ganhar o reconhecimento público.

Por "visibilidade", Heinich se refere à qualidade social, específica ao regime de mídia, pela qual um indivíduo é conferido e reconhecido pela reprodução 
e disseminação em massa de sua própria imagem ou/e nome. Ela explica: "não é a estrela que está na origem da multiplicação de suas imagens (porque, no início, há apenas uma pessoa dotada de certos talentos) mas são as imagens dele que o fazem uma estrela" (HEINICH, 2012, p. 21). Indissociável dos vetores técnicos que a produzem e disseminam, a "visibilidade" tem o interesse heurístico de desarmar qualquer forma de julgamento ideológico ou moral e, assim, oferecer um critério estável quanto à apreciação do capital de visibilidade de um indivíduo. Esse capital pode ser mensurável em número de fotografias, capas de revistas e outras ocorrências de mídia de sua própria efígie. A essa qualidade corresponde, por outro lado, um princípio de dissimetria a partir do qual a desigualdade numérica é estabelecida entre o indivíduo visto e a maioria que o vê, entre a personalidade consagrada pelo renome da mídia e a massa anônima de seus espectadores. "Esta propriedade estrutural", diz Heinich, "tem precedência sobre propriedades substanciais - talento, herança, beleza, carisma, e assim por diante - que justificam o acesso ao grau de personalidade" (2012, p. 39). Desse modo, Heinich aponta que o fenômeno contemporâneo das celebridades não deve ser reduzido unicamente à espetacularização de imagens midiáticas, pelo fato de que essas personagens são responsáveis por inaugurar um novo processo de nominação social. A celebrização facilita o surgimento de um sistema de reconhecimento, que torna possível a aparição de indivíduos singulares dentro de uma multidão de anônimos. Heinich chega à definição de capital de visibilidade partindo da análise do conceito de capital simbólico de Bourdieu. Ela argumenta que esse capital de visibilidade é regulado por normas econômicas particulares, devido ao fato de haver um aumento na disseminação de imagens ao longo do século XX, o que gerou uma definição de hierarquias sociais afetadas pelas variações desse capital de visibilidade. Nessa lógica, para ser uma celebridade - um representante de uma nova elite do poder que tivesse nascido ao longo do século XX (MILLS, 1982) - é necessário acumular e converter seu capital de visibilidade/celebridade.

O que Heinich chama de capital de visibilidade, Van Krieken e Driessens dão o nome de capital de celebridade. Van Krieken (2012) defende que as celebridades são uma característica essencial e que geram dinâmica nas sociedades ocidentais. Couldry aponta que em inúmeros campos sociais, como o campo cultural, econômico e/ou político, a celebridade é um recurso de poder 
valioso. Segundo ele, isso é constatado a partir da analogia de Couldry sobre o "mito do centro mediado" (2003), ou seja, a suposição de que os meios de comunicação seriam os portadores privilegiados e os pontos de acesso aos centros sociais imaginados. Couldry defende que há uma distinção essencialmente hierárquica entre os "indivíduos da mídia" e as "pessoas comuns". Em outras palavras, esse mito implica que estar na mídia daria a uma pessoa importância maior quando comparada com aqueles que estão fora da mídia. Como enfatiza Giles (2000, p. 5): “a realidade brutal da era moderna é que todas as pessoas famosas são tratadas como celebridades pelos meios de comunicação de massa, quer sejam uma grande figura política, um ativista, um artista ou um serial killer".

O conceito de capital de celebridade já foi apresentado, mesmo que brevemente, por Collins (2007) e Kerrigan et al. (2011). No entanto, a pormenorização conceitual veio de Driessens e, principalmente, de Van Krieken (2012). Este último descreveu a celebridade como a "encarnação mais abstrata de atenção do capital" (VAN KRIEKEN, 2012, p. 54). Como exemplo, cita os vencedores de prêmios Nobel e os sujeitos que se estabeleceram no campo em que trabalham e que recebem mais do que seus colegas menos conhecidos. Para Van Krieken, embora os profissionais que recebem menos atenção executem trabalhos em nível similar, aparecem menos por não terem capital de celebridade, que seria principalmente "uma questão de acumulação e distribuição de atenção" (VAN KRIEKEN, 2012, p. 55).

Driessens especifica que as celebridades são construídas pela mídia, pelo público e pela indústria de celebridades (DRIESSENS, 2013, p. 545). Collins (2007, p. 191) foi o primeiro autor a introduzir o conceito de capital de celebridades como parte da teoria de campo de Bourdieu. Ela definiu como "uma configuração particular de capital simbólico que é necessário (entre as outras formas de capital) para habitar e operar com sucesso como uma mercadoria cultural no campo do entretenimento" (COLLINS, 2007, p. 191). Essa formulação é rigorosa. Primeiramente, Collins limitou o capital da celebridade ao campo do entretenimento, mas como esse trabalho já mostrou, a celebridade pode ser usada como um meio de poder em muitos campos.

Para Heinich (2012), o capital da celebridade é encontrado em representações recorrentes de mídia ou de visibilidade da mídia acumulada. Nesse 
sentido, é um tipo específico de capital gerador de atenção que não pode ser reduzido ao capital simbólico. Já Driessens (2013, p. 552) defende a necessidade de separar a celebridade do capital simbólico de forma analítica: o capital de celebridade ou a visibilidade resultante da mídia não é equivalente ao capital simbólico ou ao reconhecimento. Assim, enquanto o capital simbólico geralmente é específico do campo, o capital da celebridade pode funcionar em campos sociais. Essa visão de Driessens converge com a noção de Thompson (2005, p. 49): “obter visibilidade através da mídia é ganhar uma espécie de presença ou reconhecimento no espaço público, o que pode ajudar a chamar a atenção para a situação ou para promover a causa de alguém”. Nessa linha, Driessens enfatiza: "a visibilidade da mídia precisa de renovação e repetição, portanto, o capital da celebridade é fundado em representações de mídia recorrentes. Caso contrário, ele desaparece rapidamente" (DRIESSENS, 2013, p. 552).

O capital de celebridades pode ser utilizado como empreendimento como forma de aumentar a confiabilidade, credibilidade e responsabilidade do negócio. Nesse caso, as celebridades serviriam para endossar o empreendimento. Por isso, Driessens ressalta que o capital de celebridade pode ser convertido em capital econômico, social ou político, Mesmo assim, aponta que

a conversão do capital da celebridade em outro tipo de capital nem sempre passa despercebida ou sem resistência, pois pode perturbar o valor relativo dos diferentes tipos de capital e as correspondentes dinâmicas de poder nos campos sociais. (DRIESSENS, 2013, p. 555).

Ainda seguindo Driessens, ao ampliar a teoria do campo com a noção de capital da celebridade, compreendida como visibilidade da mídia acumulada por meio de representações recorrentes da mídia, entendemos algumas das articulações midiáticas, especificamente as articulações do meta-capital da mídia, tanto para agentes individuais (celebridades) quanto para campos sociais (celebrização). O meta-capital da mídia não só influencia a definição de capital e as regras do jogo em muitos campos sociais, como a circulação das representações da mídia também pode se materializar em uma forma distinta de capital: no capital de celebridades. Logo: 
Capital de celebridade pode se tornar importante ao lado de outras formas de capital e influenciar a dinâmica e o funcionamento interno dos campos. No entanto, o capital de celebridade não é por definição e não está sendo reconhecido em todos os campos autoritariamente por outros agentes, ou traduzido em capital simbólico, certamente não no caso da infâmia. Por isso, é necessário separar o capital estritamente celebrizado e o capital simbólico. A celebridade (capital) não é, como às vezes (implicitamente) sugerida na literatura, um subconjunto ou categoria especial de capital simbólico, mas sim uma forma de capital substancialmente diferente. Não obstante o seu caráter substancial, a celebridade foi identificada como uma categoria em grande parte instável [...], como algo que pode mudar durante a noite. (DRIESSENS, 2013, p. 556).

Como Cashmore (2006) já observou, houve uma grande mudança cultural em que as celebridades assumiram uma autoridade moral frente ao seu público-alvo, sendo associado a líderes carismáticos (KAMRADT, 2020). Logo, a celebrização e seus representantes, as celebridades, são um capital próprio constituinte da sociedade contemporânea. O capital de celebridade fica visível quando um famoso desempenha funções as quais não estava habituado. É essa observação que faremos agora com o digital influencer Felipe Neto.

\section{De antipetista radical a defensor das minorias e antibolsonarista: como Felipe Neto usa o capital celebridade}

Hoje, Felipe Neto é conhecido em todo o Brasil, e a sua opinião é levada a sério, tanto no âmbito cultural quanto no político. Mas nem sempre foi assim. Em 2007, ele era um desconhecido, atuando como um dos administradores do portal de séries americanas IsFree.Tv, notabilizado pelo avatar "Cap_ Sparrow" (ARRUDA et al., 2011). Foi a partir de 2010, quando criou dois canais no YouTube 4 (Não Faz Sentido e Vlog do Felipe Neto), que passou a fazer sucesso. Nos vídeos, dialogava com jovens e adolescentes sempre optando por uma veia cômica, abordando temas debatidos na sociedade e fazendo críticas a atitudes e comportamentos de artistas. Por mais que tratasse de te-

4 Seu primeiro vídeo, de poucos segundos, era uma risada. Está disponível no link: www.youtube.com/ watch?v=jlZhSWuiFJs 
máticas variadas, Neto tinha como público final os jovens. Então, era comum o uso de gírias, frases curtas, fragmentadas e palavrões. Foi a forma direta e simples de se comunicar com a audiência que transformou Felipe Neto em um dos youtubers mais conhecidos do planeta.

De um quarto com pôsteres do ator Johnny Depp, Neto aparecia em frente às câmeras com o cabelo para cima e com óculos escuros. Os seus primeiros vídeos que viralizaram eram críticas ao cantor Fiuk, a ex-BBB Francine, além de uma publicação em que criticava a saga cinematográfica Crepúsculo. Como ressaltado por Arruda et al. (2011 p. 3), em menos de oito meses o canal já havia sido assistido por 23 milhões de pessoas, com mais de 800 mil seguidores no Twitter. "Ele ganhou fã-clube, programa de TV no canal pago Multishow, assessor de imprensa, linha de canecas e camisetas com bordões próprios como 'Você tem probleminha?', além de dezenas de entrevistas em todos os lugares" (ARRUDA et al., p. 3). Com isso, também vieram inúmeras críticas de que seu conteúdo não deveria ser assistido por jovens por deseducá-los.

O tempo só fez a audiência do digital influencer crescer. Em 2016, Felipe fechou seus canais e abriu uma produtora de vídeos de humor, focado em produções para o YouTube. Depois, fundou um canal em conjunto com seu irmão. Durante esse tempo, lançou quatro livros e se envolveu em três empresas. Em 2019, se tornou o segundo youtuber mais assistido do planeta, ficando atrás apenas do sueco PewDiePie. Somente em 2019, foram mais de 3,5 bilhões de visualizações do jovem youtuber e mais de 500 milhões de horas do seu material consumido. Ao todo, já possui mais de 9 bilhões de visualizações desde que abriu seus canais, dez anos atrás. Em outubro de 2020, por exemplo, contava com um total de 74,4 milhões de seguidores abrangendo todas as suas redes sociais. Eram 40,1 milhões de inscritos no seu canal do Youtube, 12,8 milhões no Instagram, 12,5 milhões no Twitter e 8,8 milhões no TikTok. No Facebook, teve a sua conta banida três vezes porque supostamente se passava por um famoso. Recentemente, voltou a ter um perfil na plataforma, na qual conta com 200 mil seguidores.

Hoje, Felipe Neto é visto como um forte crítico do governo Bolsonaro. Mas a sua participação política começou antes disso, pois tanto em vídeos quanto nas redes sociais apoiou o impeachment sofrido pela ex-presidente Dilma Rousseff (PT). Segundo ele, o PT havia sido o responsável por "quebrar 
o país", além de ser "um partido conivente com a corrupção, da qual inclusive fez parte ativamente e de maneira absurda" (KLEIN, 2019). Mas as críticas ao governo petista foram diminuindo, e hoje ele considera o impeachment sofrido pela petista um "golpe", embora ainda considere as medidas econômicas tomadas à época ruins para o país. Mesmo assim, em 2016, as falas políticas de Neto ainda não tinham a dimensão que receberam nos últimos três anos.

As duas primeiras ações políticas que geraram repercussão para além da bolha de seguidores de Neto foram embates com lideranças evangélicas. Em 2017, o pastor Silas Malafaia havia prometido realizar boicote contra todas as marcas que publicassem conteúdo promovendo a igualdade de direitos sexuais, o que ele considerava um atentado contra a família cristã. Isso fez Neto postar um vídeo afirmando que faria campanha de graça para todas as empresas que sofressem boicote por parte do pastor. Desde então, Malafaia não promoveu mais boicote a marcas. O caso estampou alguns dos principais jornais do país. Em 2018, após não declarar apoio a nenhum candidato no $1^{\circ}$ turno das eleições presidenciais, no $2^{\circ}$ turno Felipe Neto endossou Fernando Haddad (PT) em duas publicações, logo ele que, anos antes, foi uma voz crítica ao governo da também petista Dilma Rousseff. Segundo Neto, a mudança se deu por receio da perda de direitos que ocorreria com um governo Bolsonaro. Uma das postagens, no Twitter, foi curtida por 121 mil pessoas, retuitada por outras 29,4 mil e recebeu 9,2 mil comentários.

As duas participações aumentaram a dimensão política de Felipe, mas foi o seu confronto com Marcelo Crivella (PRB) que o fez notícia em todo o mundo. Em 2019, o então prefeito do Rio de Janeiro havia enviado fiscais para a Bienal do Livro com o objetivo de censurar o que ele entendeu ser "conteúdo sexual para menores". No caso, Crivella determinou que fossem recolhidas cópias do gibi de temática LGBTQ "Vingadores: a cruzada das crianças", na qual havia uma imagem com dois rapazes se beijando. Para evitar a ação, Neto comprou 14 mil HQs e distribuiu os exemplares gratuitamente no evento. $\mathrm{O}$ assunto ganhou a capa de jornais nacionais e internacionais. Junto com isso, o youtuber estruturou uma série de mudanças nos seus vídeos, apagando alguns do canal (a maioria com conotação sexual), enquanto outros receberam mensagens com classificação indicativa de acordo com a idade do público. 
Figura 1 - Felipe Neto compra livros proibidos por Crivella e os distribui gratuitamente
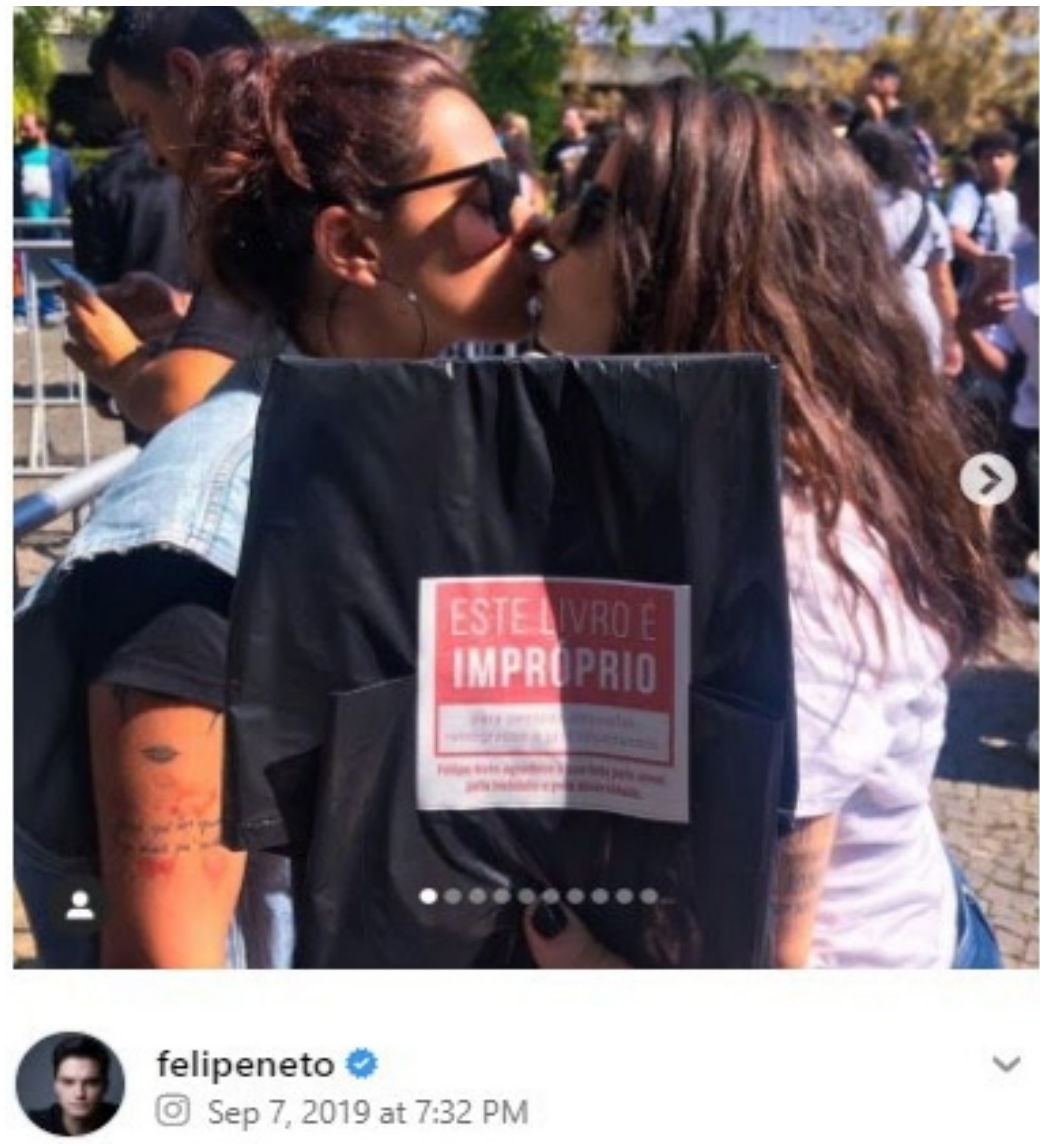

Fonte: Dados obtidos na página oficial de Felipe Neto.

O confronto com Crivella fez com que Neto passasse a se posicionar de forma mais clara sobre diversos assuntos. Foi aí que passou a se colocar contrariamente a Jair Bolsonaro e a declarar que o processo que levou o ex-presidente Lula a prisão era ilegal. Como ele disse em sua participação no programa Roda Viva: "me equivoquei por falta de estudo, leitura. Passei os últimos três, quatro anos amadurecendo e estudando para usar a minha força e tentar afastar a opressão que vivemos hoje. Vou continuar tentando evoluir e melhorar" (RODA VIVA, 2020). 
Com o início do governo Bolsonaro, Neto passou a se posicionar de forma ainda mais crítica e constante às medidas tomadas pelo presidente. Na soma das redes sociais, Felipe Neto possui mais seguidores do que todos os membros do clã Bolsonaro. Com sua postura crítica ao governo, ele revelou já ter sido convidado para se filiar a partidos de esquerda, o que recusou. Ainda em 2020, Felipe deu entrevista ao vivo no Jornal Nacional e produziu um vídeo para um dos mais respeitados jornais do planeta: o New York Times. Nesse último, explicou as razões que faziam Bolsonaro ser o pior presidente do planeta no combate à pandemia do Coronavírus. A publicação obteve 4,9 milhões de visualizações em 24 horas. As aparições na mídia irritaram o clã Bolsonaro e seus apoiadores mais do que as críticas recebidas de políticos adversários. O presidente chegou até mesmo a responder a celebridade, mas mais tarde apagou o comentário. Além disso, Felipe foi alvo de ataques e de fake news. Por fim, assim como Bolsonaro, Felipe Neto foi incluído na lista das 100 pessoas mais influentes de 2020 da revista Time, tornando-se o $12^{\circ}$ brasileiro a integrar esse elenco.

Felipe Neto é uma figura famosa que utiliza o seu capital de celebridade para articular um conjunto de políticas na sociedade em que vive, como se observa nos últimos anos. E isso atende, em grande parte, ao capital de celebridade, a qual dispõe de normas específicas reguladas principalmente pela construção constante da imagem do indivíduo. Antes das redes sociais, isso ocorria apenas por intermediação dos grandes conglomerados de comunicação. Atualmente, não é mais necessário. Basta um dispositivo tecnológico com acesso à internet somado à capacidade de editar vídeos ou fotos, além de um discurso cativante - elementos que Neto construiu ao longo dos últimos dez anos, quando saiu do anonimato e se transformou em um dos brasileiros mais conhecidos do mundo.

O capital de celebridade coloca em cena um conjunto de articulações que impactam na dinâmica de outros campos, como fala Heinich (2012) - e aí reside a sua força. Afinal, um famoso pode se comunicar diretamente com milhões de pessoas. No caso de Neto, com mais de 70 milhões de seguidores nos seus diversos perfis em redes sociais. Logo, a sua mensagem pode impactar politicamente. Mas a pergunta que fica é: os seus fãs assistem isso? No caso de Neto, sim. Sua postagem com o maior número de interações recebidas no Instagram em 2020 foi de uma foto enquanto dava uma entrevista no Jornal 
Nacional, da rede Globo, para falar sobre fake news e o seu posicionamento político crítico a Jair Bolsonaro, presidente do Brasil. Então, se durante seus primeiros anos, Neto não era reconhecido como um agente capaz de impactar politicamente, isso foi mudando ao longo dos anos - seja quando criticou Dilma, desafiou Malafaia e Crivella, seja quando se posicionou como um crítico do governo Bolsonaro. E a sua aparição em veículos tradicionais, como a rede Globo, o jornal The New York Times e a revista Time atestam isso.

Figura 2 - Felipe Neto participa do Jornal Nacional para falar sobre fake news e seu posicionamento político
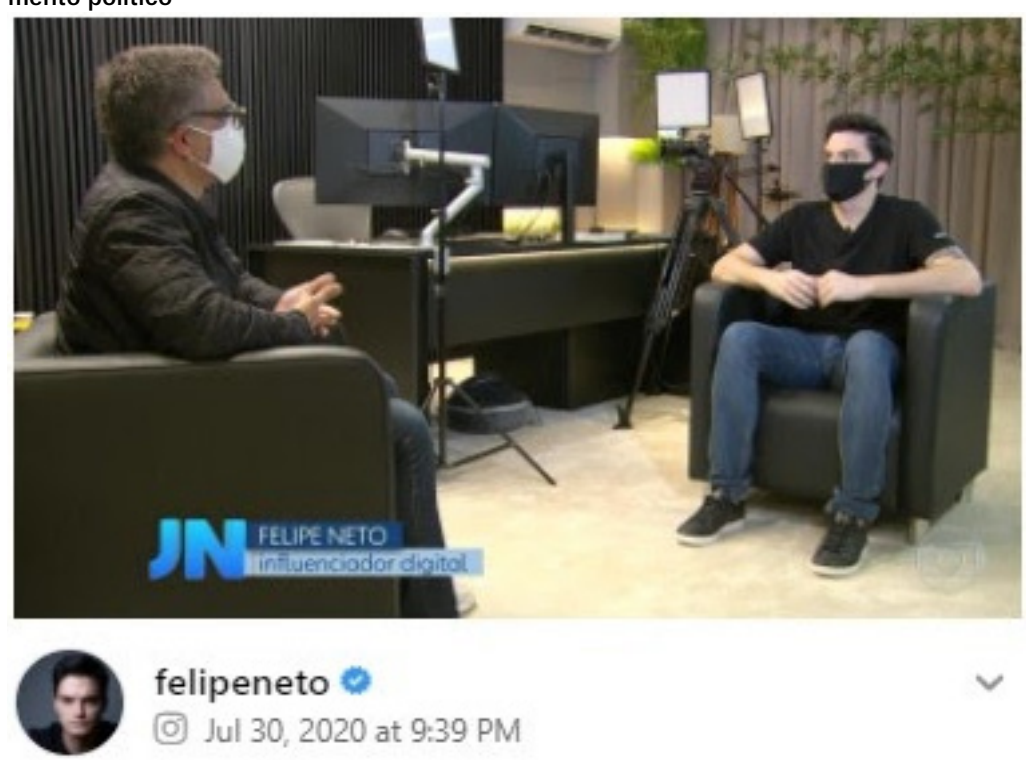

\section{Muito obrigado ao Jornal Nacional pelo espaço e por divulgar} a verdade para o povo brasileiro.

See more

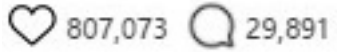

Fonte: Dad1os obtidos na página oficial de Felipe Neto.

Como aponta Van Krieken (2012), as celebridades geram novas dinâmicas nas sociedades ocidentais, sendo um ativo valioso nos mais diversos 
campos e podendo transitar entre eles com fluência e facilidade. O capital de celebridade precisa de constante renovação e repetição, caso contrário desaparece. Isso se torna mais prático quando se é um digital influencer, o qual não precisa da intermediação da mídia. Desse modo, essa situação ocorre de forma constante nos inúmeros vídeos elaborados para o YouTube, nos posts no Instagram e nos comentários feitos no Twitter. Dessa forma, Felipe Neto conseguiu operar com sucesso sua própria persona como uma mercadoria cultural dentro do campo do entretenimento. Assim, com o tempo, o seu capital de celebridade passou a ser usado para articular o campo político.

Nesse sentido, o capital de celebridade é composto pela capacidade de gerar e de reter atenção. Se bem mobilizado, quanto mais gera atenção, mais a celebridade consegue aumentar o poder de atrair os olhares dos mais diversos setores da sociedade. Nesse caso, a celebridade não precisa converter seu capital de celebridade em capital político (ao menos que deseje concorrer a um cargo público), visto que a atenção que atrai para o que fala já interfere politicamente, fazendo com que os agentes políticos se sintam compelidos a responder, como foi o caso nas disputas políticas de Neto com Crivella e Bolsonaro. E os políticos percebem e tentam limitar isso. Essa é a razão dos ataques rotineiros sofridos pelo famoso, por parte de apoiadores de políticos criticados pela celebridade ou pelos próprios políticos.

Ao perceber que o capital de celebridade tem poder de criar articulações que afetam diretamente as políticas do país, Felipe Neto percebeu que sua capacidade de gerar e reter atenção lhe dá poder político mesmo sem exercer nenhum cargo. E esse potencial pode ser usado não só contra políticos, mas também para fazer com que outros famosos se posicionem. Por isso, a celebridade já avisou que a sua postura só irá se intensificar daqui pra frente: “eu já estou avisando de antemão, em 2022 eu vou me tornar a pessoa mais odiada pelos influenciadores no Brasil. A turma toda do 'prefiro não me meter' já pode ir me odiando desde já" (NETO, 2020).

\section{Considerações finais}

De acordo com o pensamento de Bourdieu (2011, p. 206), o que está em disputa no jogo político é o monopólio da capacidade de fazer ver e de fazer crer em uma determinada direção. Assim como no campo simbólico, no 
campo político as fronteiras estão sempre em disputa. Bourdieu defendia que a política, assim como a religião, exige uma conversão do sujeito, conversão essa tacitamente imposta. Mas com o avanço das celebridades nos mais diversos campos, os políticos se viram sem opção a não ser buscar um capital que ganhou espaço juntamente com a importância que a mídia ganhou na sociedade: o capital de celebridade.

Essa conversão pode ser um atalho dos indivíduos aos políticos, já que é a partir dela que os sujeitos podem alcançar mais rapidamente os seus objetivos. Como vimos, a celebridade é uma categoria instável, que pode se alterar de um momento para o outro. Mas é na manutenção, mesmo que instável desse capital, que se torna possível o reconhecimento do capital das celebridades pelos outros (no caso, o público).

Neste artigo, argumentei que o capital de celebridade é algo que vem alterando o jogo político. Para tanto, utilizei o exemplo do digital influencer Felipe Neto, figura outrora praticamente desconhecida há dez anos e que hoje é um dos indivíduos mais assistidos do mundo. Atualmente, as suas posições políticas são utilizadas para criar articulações em outros campos, como o político. Assim, podemos perceber como ele consegue gerar e reter atenção do público e direcioná-la para pautas e políticas do seu interesse, seja criticando ou endossando um candidato, ou mesmo propondo um debate sobre determinada política pública.

Ademais, ao se definir a celebrização como um capital, também se faz possível analisar, de modo mais detalhado, como ocorre a conversão do capital de celebridade em outras formas de capital. Somado a isso, esta análise foi importante para estabelecer bases para estudos voltados a compreender como os famosos interferem na política, sem que precisem se institucionalizar, revelando, assim, novas facetas da teoria de campo e capital de Bourdieu adaptadas a uma sociedade cada vez mais digitalizada.

\section{Referências}

ABERCROMBIE, Nicholas; LONGHURST, Brian. Audiences: a sociological theory of performance and imagination. London: SAGE, 1998.

ALBERTAZZI, Danieli; McDONNELL, Duncan. Populists in power. Abingdon: Routledge, 2015. 
ARRUDA, Byanka da Silva; TEIXEIRA, Mizuko K.; BASTOS, Nayra B.; ABREU, Paulo V.; VIEIRA, YÚUK. A exposição do jovem na internet: um estudo sobre o caso Felipe Neto. Biblioteca On-line de Ciências da Comunicação (BOCC), [Online], p. 1-12, 2011. Disponível em: http://www.bocc.ubi.pt/pag/ arruda-et-al-a-exposicao-do-jovem-na-internet.pdf. Acesso em: 5 jul. 2021. BONNEWITZ, Patrice. Primeiras lições sobre a sociologia de P. Bourdieu. Petrópolis: Vozes, 2005.

BOORSTIN, Daniel. The image: a guide to pseudo-events in America. New York: Atheneum, 1971.

BOURDIEU, Pierre. A distinção: crítica social do julgamento. Porto Alegre: Zouk, 2007.

BOURDIEU, Pierre. O campo político. Revista Brasileira de Ciência Política, Brasília, n. 5, p. 193-216, 2011.

BOURDIEU, Pierre. O poder simbólico. Rio de Janeiro: Bertrand, 1989.

BOURDIEU, Pierre. O senso prático. Petrópolis: Vozes, 2009.

BOURDIEU, Pierre. Razões práticas: sobre a teoria da ação. Campinas: Papirus, 1996.

BRAUDY, Leo. The frenzy of renown. New York: Vintage Books, 1997.

CAIRNEY, Paul. The professionalization of MPs: refining the 'politics-facilitating' explanation. Parliamentary Affairs, Oxford, v. 60, n. 2, p. 212 233, 2007.

CARDO, Valentina. Celebrity politics and political representation: the case of George Galloway MP on Celebrity Big Brother. British Politics, Basingstoke, v. 9, n. 2, p. 146-160, 2014.

CASHMORE, Ernest. Celebrity culture. London: Routledge, 2006.

COLLINS, Sue. Traversing authenticities: The West Wing president and the activist Sheen. In: RIEGERT, Kristina (ed.). Politicotainment: television's take on the real. New York: Peter Lang, 2007. p. 181-211.

CORNER, John. Mediated persona and political culture: dimensions of structures and process. European Journal of Cultural Studies, London, v. 3 n. 3, p. 389-405, 2000.

CORNER, John; PELS, Dick. The restyling of politics. In: CORNER, John; PELS, Dick (ed.). Media and the restyling of politics. London: SAGE, 2003. p. 1-15. 
COULDRY, Nick. Media rituals: a critical approach. London: Routledge, 2003. DAHLGREN, Peter. Media and political engagement: citizens, communication and democracy. Cambridge: Cambridge University Press, 2009.

DAHLGREN, Peter. Television and the public sphere: citizenship, democracy and the media. London: SAGE, 1995.

DAHLGREN, Peter. The transformation of democracy? In: AXFORD, Barrie; HUGGINS, Richard (ed.). New media and politics. London: SAGE, 2001. p. 64-88. DRIESSENS, Oliver. Celebrity capital: redefining celebrity using field theory. Theory \& Society, Dordrecht, v. 42, n. 5, p. 543-560, 2013.

GABLER, Neal. Life: the movie: how entertainment conquered reality. New York: Vintage Books, 2000.

GILES, David. Illusions of immortality: a psychology of fame and celebrity. London: Macmillan, 2000.

GOMES, Wilson. Democracia digital: que democracia. In: ENCONTRO DA ASSOCIAÇÃO NACIONAL DE PESQUISADORES EM COMUNICAÇÃO E POLÍTICA, 2., 2007, Belo Horizonte. Anais [...]. Belo Horizonte: UFMG, 2007. v. 5, p. 1-29. Disponível em: http://www.compolitica.org/home/wp-content/uploads/2011/01/gt_ip-wilson.pdf. Acesso em: 5 jul. 2021.

GOMES, Wilson. Transformações da política na era da comunicação de massa. São Paulo: Editora Paulus, 2004.

HART, Roderick. Seducing America: how television charms the modern voter. New York: Oxford University Press, 1999.

HEINICH, Nathalie. De la visibilité: excellence et singularité en régime médiatique. Paris: Editions Gallimard, 2012.

HOLMES, Mary. The emotionalization of reflexivity. Sociology, Cambridge, v. 44, n. 1, p. 139-154, 2010.

INTHORN, Sanna; STREET, John. 'Simon Cowell for prime minister'? Young citizens' attitudes towards celebrity politics. Media, Culture \& Society, London, v. 33, n. 3, p. 1-11, 2011.

KAMRADT, João. A celebrização como sucessora do carisma ou como contrapartida secular? O papel dos famosos na sociedade contemporânea. Estudos de Sociologia, Araraquara, v. 25, p. 249-266, 2020. KERRIGAN, Finola; BROWNLIE, Douglas.; HEWER, Paul; DAZA-LETOUZE, Claudia. 'Spinning' Warhol: celebrity culture theoretics and the logic of 
the brand. Journal of Marketing Management, London, v. 27, p. 15041524, 2011.

KERTZER, David. Political rituals. In: CHELES, Luciano; SPONZA, Lucio (ed.). The art of persuasion: political communication in Italy from 1945 to the 1990s. Manchester: Manchester University Press, 2011. p. 99-112.

KLEIN, Cristian. Felipe Neto, o empresário e youtuber que incomoda Bolsonaro.

Entrevistado: Felipe Neto. Valor Econômico, Rio de Janeiro, 15 set. 2019. Disponível em: https:/valor.globo.com/noticia/2019/09/15/felipe-neto-o-empresario-e-youtuber-que-incomoda-bolsonaro.ghtml. Acesso em: 5 jul. 2021.

LANA, Lígia. A vítima oportunista: a construção da celebridade Luciana Gimenez. Interseções, Rio de Janeiro, v. 15, n. 2, p. 446-462, 2013.

MANNING, Nathan; HOLMES, Mary. Political emotions: a role for feelings of affinity in citizens' (dis)engagements with electoral politics? Sociology, Cambridge, v. 48, n. 4, p. 698-714, 2014.

MARSH, David; 'T HART, Paul; TINDALL, Karen. Celebrity politics: the politics of the late modernity? Political Studies Review, Oxford, v. 8, n. 3, p. 322-340, 2010.

MARSHALL, P. David. Celebrity and power: fame in contemporary culture. Minneapolis: University of Minnesota, 1997.

MEYER, Thomas. Democracia midiática: como a mídia coloniza a política. Rio de Janeiro: Loyola, 2008.

MILLS, Charles Wright. As celebridades. In: MILLS, Charles Wright. A elite do poder. Tradução de Waltensir Dutra. Rio de Janeiro: Zahar, 1982. p. 88-115. NETO, Antônio Fausto. Fragmentos de uma analítica da midiatização. MATRIZes, São Paulo, n. 2, p. 89-105, 2008.

NETO, Felipe. Errei muito no passado e aprendi muito com meus erros [...].

Twitter: @felipeneto. Rio de Janeiro, 18 maio 2020. Disponível em: https://twitter.com/felipeneto/status/1262550710723514370. Acesso em: 23 abr. 2021.

RODA VIVA | Felipe Neto | 18/05/2020. [S. l.: S. n.], 2020. 1 vídeo (1h 36min 17segs). Publicado pelo canal Roda Viva. Disponível em: https://www.youtube.com/watch?v=KQ1CQqNveac. Acesso em: 5 jul. 2020.

ROJEK, Chris. Celebridades. São Paulo: Rocco, 2008. 
RUBIM, Antônio A. C. Comunicação e política: conceitos e abordagens. Salvador: Editora UFBA, 2004.

SELL, Carlos Eduardo. A secularização como sociologia do moderno: Max Weber, a religião e o Brasil no contexto moderno-global. Revista Brasileira de Sociologia, [Online], v. 3, n. 6, p. 11-46, 2015.

SIMÕES, Paula. G. Celebridade e contexto contemporâneo. Galáxia, São Paulo, n. 28, p. 45-57, 2014.

STREET, John. Celebrity politicians: popular culture and political representation. The British Journal of Politics \& International Relations, [Online], v. 6, n. 4, p. 435-452, 2004.

STREET, John. Do celebrity politics and celebrity politicians matter? The

British Journal of Politics and International Relations, [Online], v. 14, n. 3, p. 346-356, 2012.

STREET, John. Politics and popular culture. Cambridge: Polity Press, 1997. STREET, John. Rebel rock. London: Blackwell, 1986.

THOMPSON, John. The media and modernity: a social theory of the media.

Cambridge: Polity Press, 2005.

TURNER, Graeme. Understanding celebrity. London: SAGE, 2004.

VAN KRIEKEN, Robert. Celebrity society. London: Routledge, 2012.

VAN ZOONEN, Liesbet. Entertaining the citizen: when politics and popu-

lar culture converge. New York: Rowman and Littlefield Publishers, 2005. WEBER, Max. Economia e sociedade: fundamentos da sociologia compreensiva. Brasília: Editora UnB, 2012. v. 2.

WEST, Darrell; ORMAN, John. Celebrity politics. New Jersey: Prentice Hall, 2002.

WHEELER, Mark. The democratic worth of celebrity politics in an era of late modernity. British Journal of Politics and International Relations, [Online], v. 14, n. 3, p. 407-422, 2012.

O capital celebridade e suas articulações em outros campos: a teoria de Bourdieu estendida e o caso de Felipe Neto

Resumo: Em uma sociedade em que os indivíduos vivem por e através de representações, as celebridades possuem um papel fundamental. Neste artigo, procuro apontar que a celebrização é um capital. Assim, a teoria de campo 
e de capital de Bourdieu precisa ser estendida. A partir do exemplo do digital influencer Felipe Neto, revelo como esse capital vem sendo utilizado. Mais do que atuarem no campo midiático ou do entretenimento, os famosos influenciam e participam ativamente do processo político. Por isso, é necessária uma redefinição do papel do indivíduo que acumula capital de celebridade, resultado da visibilidade midiática acumulada e de aparições midiáticas recorrentes. Somente assim é possível compreender o efeito do capital de celebridade em outros campos, como o político e/ou econômico.

Palavras-chave: Capital de celebridade; famosos; política; mídia; Felipe Neto.

\section{Celebrity capital and its connections to other fields: an extension of Bourdieu's theory and the case of Felipe Neto}

Abstract: In a society in which individuals live for and through representations, celebrities have a key role. In this article, I try to show that being a celebrity is a capital. Thus, Bourdieu's field and capital theory needs to be extended. Based on the example of the digital influencer, Felipe Neto, I reveal how this capital has been used. Beyond acting in the media or entertainment fields, famous people influence and actively participate in the political process. It is therefore necessary to redefine the role of the individual who accumulates celebrity capital, the result of accumulated media visibility and recurrent media appearances. Only then can we understand the effect of celebrity capital on other fields, such as politics and/or the economy.

Keywords: Celebrity capital; famous; politics; media; Felipe Neto.

Recebido em 17 de dezembro de 2020

Aprovado em 23 de abril de 2021. 